\title{
Marker assisted gene introgression in to common bean (Phaseolus vulgaris I) against angular leaf spot (Pseudosercospora griseola) and anthracnose (Colletotrichum lindemuthianum)
}

\author{
Melese Lema ${ }^{1 *}$, Hewan Demissie ${ }^{2}$ and Yayis Rezene ${ }^{1}$ \\ 1'Department of Plant Breeding, Crop Research Directorate, Southern Agricultural Research Institute, Arbaminch \\ Research Center, Arbaminch, Ethiopia. \\ ${ }^{2}$ Collage of Plant Science and Horticulture, Hawasa University, Hawasa, Ethiopia. \\ *Corresponding author. Email: meleselema72@gmail.com
}

Copyright (C) 2021 Lema et al. This article remains permanently open access under the terms of the Creative Commons Attribution License 4.0, which permits unrestricted use, distribution, and reproduction in any medium, provided the original work is properly cited.

Received 29th April, 2021; Accepted 10th July, 2021

\begin{abstract}
Angular leaf spot (ALS) and Anthracnose (ANT) are important diseases of common bean in Ethiopia. This study was conducted to pyramid resistant genes for ALS and ANT diseases into advanced line and to evaluate isolines against ALS and ANT using marker assisted selection in combination with phenotypic selection. The parent AND277 donor of Phg-1 and Co- $1^{4}$ genes for ALS and ANT respectively and the recipient KT-ABC001 line was used for this experiment. In genotypic selection, SSR and SCAR marker were used. Marker assisted backcrossing procedure was adopted and inheritances for resistant genes were characterized by using F2 and backcrosses. The Chi-square values showed no significant differences for ALS and ANT, $0.05(p<0.78)$ and $0.03(p<0.9)$ in genotypic and phenotypic selection respectively. The narrow sense heritability for ALS and ANT were 0.97 and 0.95 implying that selection for ALS and ANT can be done at early stage in a segregating population. Correlation values for ALS $(r=-0.65)$ and for ANT $(r=-0.73)$ were obtained between phenotypic and molecular data respectively. Eight gene pyramid groups were developed and evaluated against ALS and ANT. The gene pyramid group means were significantly different from each other $(p<0.01)$ of which, Phg1+phg2+co1 ${ }^{4}+\mathrm{cbb}$ qtl and Phg $-1+\mathrm{Co}-1^{4}+\mathrm{cbb}$ QTL exhibited the lowest mean disease score to the three pathogens indicating both a high degree and a broad spectrum of resistance. The study identified three isolines with all four desirable genes. In general, pyramiding multiple genes for durable resistance using MAS in combination with phenotypic selection is invaluable for breeding program.
\end{abstract}

Keywords: Common bean diseases, durable resistance, marker- assisted selection, molecular markers.

\section{INTRODUCTION}

Common bean (Phaseolus vulgaris L.) is one among the principal grain legumes of eastern and southern Africa, occupying quite 4 million hectares annually and providing food for over 100 million people (Wortmann et al., 1998). Its production in Sub-Saharan Africa is around 35 million metric tons with $62 \%$ being produced in East African countries, namely Burundi, DR Congo, Ethiopia, Kenya, Rwanda, Tanzania and Uganda (Broughton et al., 2003). In Ethiopia, the most cultivation of common bean is within the Eastern, Southern, South-western, and rift valley regions of the country (Habtu et al., 1996). Despite its economic significance and a large area of production, current national productivity is $1.5 \mathrm{t} / \mathrm{ha}$, which is less than the potential yield of $4.5 \mathrm{t} / \mathrm{ha}$ (CSA, 2014).

The low national yield might be attributed to varied constraints (Habtu et al., 1996). A recent study revealed that pests and diseases are ranked second important production constraints within the Central rift valley region, next to drought (Habtu et al., 1996). Moreover, Yesuf (2005) emphasized that diseases are known to be the key 
factors that threaten the productivity of beans generally and common bean especially. Anthracnose (Colletotrichum lindemuthianum), angular leaf spot (Phaeoisariopsis griseola), and common bacterial blight (Xanthomonas axonopodis pv. phaseoli) are common diseases of bean in Ethiopia (Habtu et al., 1996). It has been confirmed that the infection of susceptible cultivars in favorable environmental conditions resulting in a plague could end in a 100\% yield loss (Fernandez et al., 2000). A study by Tesfaye (1997) showed that yield loss up to $62.8 \%$ by anthracnose (ANT) and Angular leaf spot (ALS) is 70\% (De Jesus Junior et al., 2001). The effect of common bacterial blight (CBB) was reported varying between $22 \%$ and $45 \%$ (Wallen and Jackson, 1975; e Silva et al., 1989).

The current disease prevention and control measures, like crop rotation, cultivar mixtures, and use of fungicides, have little impact on the disease (Deeksha et al., 2009). Moreover, these prevention and control measures cannot be fully practiced because of land shortage and also the high cost of fungicides (Deeksha et al., 2009). The use of genetic resistance is thus far the foremost effective control measure, and least expensive and easiest for farmers to adopt and use because resistance would be embedded in genetic makeup of the seed (Burkett-Cadena et al., 2008).

A couple of resistant genotypes like AND277, MEX-54, and Vax-6 are identified for those diseases (Caixeta et al., 2005). Genetic studies on these sources revealed that, AND277 is immune to ALS and ANT (Caixeta et al., 2005), Mex- 54 carries gene Phg-2, which is liable for resistance against ALS race 63:39 (Namayanja $A$ et al,.2006) and is linked to SCAR marker (Miller T et al, .2018). VAX-6 is analogous to the center American gene pool and was developed at CIAT, Cali, Colombia and immune to CBB (Xanthomonas axonopodis pv. Phaseoli) (Singh et al., 1991). SCAR markers available in screening for CBB are SU91, BC420, SAP 6, BAC 6, R7313 and R4865; SSR markers available are TGA1.1, g796 and SNO-02 screening for ALS and CV542014 is screening for ANT. These sources of resistance are often useful in facilitating the method of transferring ALS, ANT and CBB resistance into susceptible advanced lines (recurrent parents), and the resistant sources are more adapted to conditions in areas where they were developed (Abawi, 1989). As an example, AND277 and Vax-6 are medium to large-seeded cultivars, their low yields compared to popular landraces and commercial varieties and are not easily accepted by farmers in Africa (Beebe et al., 2011; Clare et al., 2010). These factors limit the direct release of resistant cultivars from available ALS, ANT and CBB resistance sources in Africa still, they are used as sources for resistant gene and during improvement their undesirable character would be reduced by back-crossing to recurrent-parent and by marker- assisted selection.

Furthermore, durable resistance within the prevailing resistance sources is challenged by pathogen variability. Due to $P$. griseola, Colletotrichum lindemuthianum and Xanthomonas axonopodis pv. Phaseoli variability, resistance often breaks down as new and more virulent strains of the pathogen evolve and/or the prevailing strains adapt to the host (Chen et al., 1993). Over time, resistant cultivars gradually become ineffective. Additionally, no single resistant gene is effective against all races of ALS, CBB and ANT; hence, protection conferred by one gene against a hyper variable pathogen is usually short lived (Mahuku et al., 2002). Considering that there are different $P$. griseola, Xanthomonas axonopodis pv. Phaseoli and Colletotrichum lindemuthianum races; the breeding technique like marker assisted gene pyramiding which will address several constraints or diseases races could probably be the proper direction in managing ALS, CBB, and ANT in Ethiopia. Pyramiding resistance genes into one genotype is one among the sensible approaches through which durable resistance are often achieved (Castro et al., 2003). The work aimed toward incorporating resistance genes to angular leaf spot and anthracnose diseases into one advanced line using molecular marker assisted selection technique. Lack of improved common bean disease resistant cultivars has been identified as major constrain in production (Pastor-Corrales and Tu, 1989) Common bean bacterial blight, angular leaf spot and anthracnose diseases are extremely devastating diseases causing high yield loses in common bean.

Disease management using chemicals is pricey thus; many smallholder farmers cannot afford, among several control strategies, integration of host plant resistance is that the best and appropriate method which is affordable to small scale resource poor farmers (Allen et al., 1998). Improvement of bean genotypes for single traits is laborious and time consuming, but using genotypes that have resistance to multiple constraints can increase the efficiency of improving bean genotype. Since, diseases in common bean have become major problems, especially for smallholder farmers. Durable resistant varieties to many disease causing pathogens are getting a priority for the farmers. Thus, there is a requirement to produce varieties which are resistance to major pathogens by using marker-assisted gene pyramiding technique to hurry up the breeding for resistance, with the general objective of developing pyramided lines of common bean with different traits and contribute to the variety development with durable disease resistance and specific objective of incorporating genes conferring resistance against Anthracnose and Angular leaf spot to selected line with the help of molecular markers and evaluating the differential reaction of common bean isoline carrying different combinations of angular leaf spot, anthracnose and common bacterial blight resistance genes.

\section{MATERIALS AND METHODS}

\section{Genotypes used}

The genotypes utilized in this study included one donor genotype (AND277) which contain resistant genes (Phg-1) to angular leaf spot and anthracnose (co-14) and one 
advanced recurrent line KT-ABC 001; breed from Red wolaita *Mex-54 x Red wolaita*Vax-6 which consists of resistant gene (Phg-2) for angular leaf spot common bacterial blight (CBB QTL). It is an elite breeding line developed from Red wolaita, Mex-54 \& Vax-6 through backcross breeding for the southern region. And which is vulnerable to both angular leaf spot (ALS) and anthracnose (ANT) diseases and to which resistance gene is to be incorporated.

\section{Marker assisted gene pyramiding and generation of breeding population}

Planting was done in the screen house in pots crammed with sterilized forest soil and maintained within the screen house at Southern Agricultural Research Institute, Hawasa, Ethiopia. Selected breeding population were developed through hybridization; the crossing procedures used was emasculation and followed hook method as described by Bliss (1980) and Buishand (1956) and backcross breeding method was adopted to reduce drag linkage during the recovery of recurrent parent.

The minimum population size to make sure of a predetermined probability of $95 \%$ or $99 \%$, that a minimum of one desired genotype is present within the population was derived from the equation:

$\mathrm{Nq}=\ln (1-\mathrm{q}) / \ln (1-\mathrm{p})$

Where; $\mathrm{N}=$ minimum population size, $\mathrm{p}=$ number of individuals of the desirable genotype in a population of size $\mathrm{N}$ and $\mathrm{q}=$ predetermined ( $\mathrm{Ye}$ and Smith, 2008).

Sequence Characterized Amplified Region (SCAR) \& Single Sequence Repeats (SSR) Molecular markers were to check for the presence of the specified character both on the donor and recurrent parents. During crossing, the ALS and ANTH disease resistance genes were incorporated into the advanced line, (KT-ABC001 $\times$ AND277). The highly resistant parent AND277 (Co-1 ${ }^{4}$ \& Phg-1) was crossed with KT-ABC001 line (with known locus Phg-2 and CBB QTL) under screen house conditions and 50 seeds of $\mathrm{F} 1$ plants were obtained. Before crossing with the recurrent parent, the molecular markers SAP-6, g796, TGA1.1 and CV542014 were run on extracted DNA of $30 \mathrm{~F} 1$ plants of the cross [(KT-ABC001 x AND277]. DNA of $20 \mathrm{~F} 1$ plants positively amplified all the four desired angular leaf spot anthracnose and common bacterial blight resistance genes (Phg-1\&Phg-2, Co- $1^{4}$ and CBB QTL) respectively. Those $20 \mathrm{~F} 1$ plants were selected and crossed with the recurrent parent to produce $\mathrm{BC} 1.45$ seeds of the back- cross [KT-ABC001 x F1] were harvested and 30 seeds replanted for next crossing. Molecular markers SAP-6, g796, TGA1.1 and CV542014 were run on DNA extracted from 30 plants $\mathrm{BC} 1 \mathrm{~F} 1$. Five plants possessing all anthracnose, angular leaf spot and common bacterial blight resistance genes in heterozygous state were obtained and those five plants were selfed to advance and fix the genes and 42 seeds of BC2F2 harvested. From total harvest; 20 seeds (isolines) were planted for genotypic and phenotypic evaluation against ALS, ANT and CBB pathogens. Three plants possessing all the four desired genes, five plants possessing three desired genes, four plants possessing two desired genes and 6 plants possessing single desired gene and two plants possessing none of desired genes were identified by combined evaluation of phenotypic and genotypic techniques. Selfing continued up to only F2 generation due to insufficient time to finish thesis and it is continued by mega project to make sure that the genes were fully fixed in homozygous state.

\section{Markers used for molecular screening}

Sequence Characterized Amplified Regions (SCAR) and simple Sequence Repeat (SSR) markers were used (Table 1) to tag anthracnose, common bacterial blight and angular leaf spot resistance genes of interest respectively.

The primers were obtained from the Department of Molecular and Cellular Biology, University of California Davis. A 25/100 bp mixed DNA molecular weight marker (Ladder), specifically designed for determining the size of double strand DNA from 25 to 2,000 base pairs, was used. TGA1.1 and CV542014 markers were used for forward selection to verify the presence of the desirable genes during which absent within the recurrent parent, SAP6 and g796 markers were used for background selection to verify the presence of the desirable genes of the recurrent parent.

\section{Marker assisted selection (MAS)}

\section{DNA extraction, PCR and gel electrophoresis}

DNA extraction: The recurrent parent (KT-ABC 001), donor parent (AND277), hybrid of parent one and parent two (F1) and backcross to both parents (BC) were planted in pots within the screen house and leaf samples for DNA extraction were collected from 14 days old leaves of seedlings at trifoliate stage.

The DNA was extracted using the Whatman FTA card technology (Whatman FTA Protocol BD08). The leaves were crushed on the FTA plant saver card and therefore the DNA binds to the matrix of the cardboard. The chemical coating on the FTA card can inactivate pathogens, protect the DNA from degradation and allows the cards to be stored at room temperature for extended period of time. To prepare sample for polymerase chain reaction (PCR), a $2 \mathrm{~mm}$ disc of the matrix was punched employing a Harris Unicore and put within the $0.2 \mathrm{ml}$ PCR tube. Then discs were washed with FTA purification 
Table 1. PCR-based markers utilized in Marker Assisted Selection.

\begin{tabular}{lllcc}
\hline No & Marker & Sequence & Linkage group & Base pair \\
\hline 1 & TGA1.1 & F 'CAGAGGATGCTTCTCACGGT' & 01 & 570 \\
& R 'AAGCCATGGATCCCATTTG & & \\
2 & CV542014 & $\begin{array}{l}\text { F 'CACTTTCCACTGACGGATT TGAACC' } \\
\text { R 'GCACAAGGACAAGTGGTCTGG' }\end{array}$ & 01 & 450 \\
3 & FAP6 & R 'GTCACGTCTCCTTAATAGTA' & 10 & 820 \\
4 & F796 'GAGAAACTACGGGCTGTTTTACCC' & \multirow{2}{*}{08} & 230 \\
\hline
\end{tabular}

Source: (Caixeta et al., 2005).

reagent and Iso-propanol. The washed leaf discs within the PCR tubes were left to dry at room temperature for five min. The DNA remains bound to the matrix throughout purification process; thus, the matrix provides enough templates for PCR analysis.

DNA amplification: The PCR reaction was prepared by adding $2 \mu \mathrm{l}$ of every forward $(F)$ and reverse $(R)$ primers, $21 \mu \mathrm{l}$ of molecular grade-water within the beads (other PCR components), $2 \mathrm{~mm}$ disc of DNA (washed FTA card) was added and a complete of $25 \mu$ l of the reaction mixture were prepared and PCR were run using BIO RAD "MyCycler" thermal cycler machine. The PCR conditions were set to correspond to every primer requirement in terms of number of cycles and therefore the temperatures as per Miklas et al. (2009).

Gel electrophoresis and documentation: A 1.5\% agarose was used and gel was prepared by mixing $1.5 \mathrm{gm}$ of agarose with $100 \mathrm{ml}$ of 1XTAE buffer then $10 \mu \mathrm{l}$ of the PCR products were loaded into the gel for electrophoretic separation of DNA fragments in a solution of 1XTAE buffer with electric potential maintained at $90 \mathrm{~V}$ for $70 \mathrm{~min}$ run time. The gel was stained with $0.5 \mu \mathrm{g} / \mathrm{ml}$ ethidium bromide $(\mathrm{EtBr})$ for $30 \mathrm{~min}$ then visualized using UV transilluminator. For documentation, camera was wont to capture the amplified fragments from the gel on the UV trans-illuminator.

\section{Inoculum collection, preparation and inoculation}

\section{Inoculum collection}

Isolates of ALS, ANT and CBB or the inocula that were used was collected from major common bean growing areas of Ethiopia specifically; Sidama, Wolaita, Gamo, Gofa and Wolega. Sample collection sheets were used and every one important information was recorded. Samples were collected from naturally infected fields with typical symptoms of the respective disease.

The inocula were stored in paper envelopes then labeled with the outline of bean variety and the location where the inoculum was collected. For ALS, the infected part of the leaf indicating the presence of fungal spores were isolated and plated into V8 agar. For inoculum preparation, well established fungal colonies were sub-cultured onto fresh medium. The plates containing isolates of fungal spores were incubated at $24^{\circ} \mathrm{C}$ for 10 to 15 days to permit for sporulation (Aparício, 1998). Following sufficient sporulation, sterile water containing $0.05 \%(\mathrm{v} / \mathrm{v})$ Tween 20 was added to the plates and the medium surface scraped smoothly employing a sterile syringe needle and the spore suspension was filtered using sterile gauze and the final spore concentration adjusted to $2 \times 104$ spores $/ \mathrm{ml}$ using the hemocytometer and prepared for inoculation.

For Anthracnose, single-spore isolates were placed on fresh Mathur's agar medium in a Petri dish and incubated at 22 to $24^{\circ} \mathrm{C}$ for 7 days to permit the fungus enough time to produce conidial spores. For inoculation purposes, conidial spores were scrapped off the growth medium into a little amount of water to form a suspension. Employing a hemocytometer, the concentration was adjusted to $1.2 \mathrm{x}$ $10^{6}$ conidia $\mathrm{ml}^{-1}$. $0.1 \%$ Tween 20 was added as a surfactant.

For common bacterial blight, differential media was prepared following the procedures described by Mortensen (2005). The stored culture of Xap was revived by growing it on Yeast Dextrose Carbonate Agar (YDCA) media plates at $28^{\circ} \mathrm{C}$ for $48 \mathrm{hr}$. Cell suspensions were made using distilled water and concentration was adjusted to $106 \mathrm{cfu} \mathrm{ml}^{-1}$ using hemocytometer.

\section{Artificial inoculation}

The parents (AND277 and KT-ABC001) and progenies (F1, F2, BC1F1P1, BC1F2P1, BC2F1P1, BC2F2P1 and BC1F1P2) additionally Red wolaita (Susceptible check) were planted in five-liter buckets in the screen house and from each, 30 seeds were used and evaluated. A randomized complete design (CRD) with three replications was adopted. The technique of artificial inoculation were divided into two set; one set was inoculated with ALS and 
ANTH isolate using detached leave technique in laboratory (Xu and Crouch, 2008; Rezene et al., 2018). Starting from 14 days after planting, leaf trifoliate was detached after approximately two thirds of their full development. Each detached trifoliate was inoculated by immersion within the suspension containing $C$. lindemuthianum and $P$. griseala spores at a degree of $1.2 \times 10^{6}$ and a couple of $\times 10^{4} \mathrm{ml}^{-1}$ respectively. The inoculated leaf trifoliate were placed inside the Petri dish containing moistened paper towels (cotton) and the Petri dish were tightly placed to permit for humidity build-up.

And the other set was inoculated with CBB isolate in green house by wounding the leaves of plants and spraying on the leaves. The isolates were inoculated at an amount of $2 \times 10^{4}$ conidia $\mathrm{ml}^{-1}$.

\section{Phenotypic and genotypic evaluation for inheritance of resistant genes}

For segregation study, parents (KT-ABC001 and AND277), RW, F1, F2 and backcrosses (F1, F2, BC1F1P1, BC1F2P1, $\mathrm{BC} 2 \mathrm{~F} 1 \mathrm{P} 1, \mathrm{BC} 2 \mathrm{~F} 2 \mathrm{P} 1$ and $\mathrm{BC} 1 \mathrm{~F} 1 \mathrm{P} 2)$ generations were used and evaluated phenotypically in the screen house for CBB and in laboratory for ALS and ANT in detached leave inoculation. Genotyping for disease resistance was done in the laboratory by extracting DNA of every generation.

For the phenotypic assessment, the data were taken as scores on a 1 to 9 CIAT scale, where by plants with disease score of 1 to three are considered to be resistant, 4 to 6 ; intermediate resistant and 6 to 9; susceptible (CIAT, 1987).

\section{Phenotypic and genotypic evaluation of isolines against ALS, ANT and CBB pathogens}

For disease reaction, parents (KT-ABC001 and ND277), 20 isolines (BC2F2) and additionally Red Wolaita as susceptible check were phenotypically evaluated in the screen house for CBB and laboratory for ALS and ANT in detached leaves.

For the phenotypic assessment, the data were taken as scores on a 1 to 9 CIAT scale, where by plants with disease score of 1 to 3 are considered to be resistant, 4 to 6 ; intermediate resistant and 6 to 9; susceptible (CIAT, 1987).

In genotyping, the evaluation was based on the presence of the gene or absence of the gene as revealed by banding pattern within the gel and this was done by using molecular markers to predict the presence or absence of the gene. A score of 1 is for the presence and a score of 0 is for the absence of the named gene.

Disease symptoms on plants inoculated with ALS and ANTH were evaluated from 6 to 14 days after inoculation at 3 days interval disease symptoms on plants inoculated with CBB were evaluated from 7 to 21 days after inoculation at 3 days interval. A 1 to 9 scale described by CIAT (1987) was used to score disease symptoms.
Data were collected from the screen house and laboratory as disease score and observation were made to the first appearance of the disease symptoms. Disease scoring was performed starting from the first week at 3 day interval for a total of 2 weeks for ALS and ANTH and 3 weeks for CBB consecutively.

The molecular data was scored in lab from the gel, a score of 1 was for the presence of marker and a score of 0 was for the absence as revealed by the banding pattern within the agarose gel.

The disease score data were subjected to the SAS for phenotypic data analysis and therefore the chi-square test was adopted to test the phenotypic segregation of the populations from the crosses between recurrent and donor parents.

Molecular data were also subjected to AMOVA for molecular data and ANOVA for initial and final disease severity were done using GenAlex (6.51) and SAS (9.2) software respectively. Means among each score were separated using least significant difference (LSD) at $5 \%$ probability level.

Molecular data were also subjected to the chi-square test to assess the gene segregation pattern of the populations derived from the two crosses using GenAlex (6.51). A correlation study was done to match the molecular marker data with the phenotypic expression of the diseases. The heritability was also studied from the variances from the distribution of the score data for the diseases.

\section{RESULT AND DISCUSSION}

\section{Phenotypic and molecular marker evaluation of angular leaf spot resistant gene inheritance}

The disease symptom development started during the first week after inoculation. The symptoms were observed to be skewed on different ends among the parents, while in AND277 the score was within the resistant side (1 to 3 ) and in recurrent parent (KT-ABC001) line and Red wolaita, on the susceptible side ( 7 to 9 ). Within the F1 populations, the score was also within the resistant side with few susceptible plants as it was expected. The F2 populations, the scores were distributed along the scale but it skewed to the left side showing more of the resistant plants than the susceptible ones. In backcrosses, the distribution was almost normal in showing equal distribution of plants among the susceptible and resistant ones and in BC1F1P1. The frequency of phenotypic classes within the disease score for resistance and susceptibility reaction to the pathogen in F1, F2 and backcross populations obtained from the cross between KT-ABC001 with AND277 and therefore the segregation classes as per molecular marker g796 for Phg-2 and CV542014 for Phg1 gene for ALS resistance are shown in Table 3. Segregation ratios were 3:1 (resistant: susceptible) for the F2 populations in both the phenotypic evaluation and 
Table 2. Frequencies of phenotypic and genotypic classes for ALS resistance.

\begin{tabular}{|c|c|c|c|c|c|c|}
\hline \multirow{2}{*}{ Parent/Cross/Marker } & \multirow{2}{*}{ Generation } & \multicolumn{2}{|c|}{ Number of plants } & \multirow{2}{*}{ Expected ratio } & \multirow{2}{*}{$x^{2} c$} & \multirow{2}{*}{$\begin{array}{c}x^{2} t \text { at } \\
\mathrm{df}(1)=3.84\end{array}$} \\
\hline & & Resistance & Susceptible & & & \\
\hline KT-ABC & P1 & 7 & 23 & - & - & - \\
\hline AND277 & $\mathrm{P} 2$ & 24 & 6 & - & - & - \\
\hline $\mathrm{P} 1 \times \mathrm{P} 2$ & F1 & 17 & 13 & $1: 1$ & - & - \\
\hline $\mathrm{F} 1 \times \mathrm{F} 1$ & F2 & 21 & 9 & $3: 1$ & 0.18 & 3.841 \\
\hline $\mathrm{P} 1 \times \mathrm{F} 1$ & $\mathrm{BC} 1 \mathrm{~F} 1$ & 14 & 16 & $1: 1$ & - & - \\
\hline $\mathrm{P} 2 \times \mathrm{F} 1$ & $\mathrm{BC} 1 \mathrm{~F} 1$ & 27 & 3 & $1: 0$ & 1.16 & - \\
\hline $\mathrm{P} 1 \times \mathrm{BC} 1 \mathrm{~F} 1$ & $\mathrm{BC} 1 \mathrm{~F} 2$ & 17 & 13 & $1: 1$ & - & - \\
\hline $\mathrm{P} 1 \times \mathrm{BC} 1 \mathrm{~F} 2$ & $\mathrm{BC} 2 \mathrm{~F} 1$ & 18 & 12 & $1: 1$ & - & - \\
\hline $\mathrm{P} 1 \times \mathrm{BC} 2 \mathrm{~F} 1$ & BC2F2 & 16 & 14 & $1: 1$ & 0.03 & - \\
\hline g796(Phg-2) & $\mathrm{BC} 2 \mathrm{~F} 2$ & 12 & 8 & $1: 1$ & 0.45 & - \\
\hline CV542014(Phg-1) & $\mathrm{BC} 2 \mathrm{~F} 2$ & 10 & 10 & $1: 1$ & 0.05 & - \\
\hline
\end{tabular}

Table 3. Correlation between ALS, ANT, CBB pathogen and TGA1.1, CV541420, g796, SAP-6 markers.

\begin{tabular}{l|cccccc}
\hline & ALS & ANT & CBB & TGA1.1 & CV5414 & g796 \\
\hline ANT & 0.379 & - & - & - & - & - \\
CBB & 0.217 & 0.090 & - & - & - & - \\
TGA1.1 & -0.151 & -0.739 & -0.122 & - & - & - \\
CV5414 & -0.658 & -0.175 & -0.245 & 0.415 & - & - \\
g796 & -0.283 & -0.398 & -0.417 & 0.016 & -0.195 & - \\
SAP-6 & -0.318 & -0.270 & -0.699 & 0.038 & 0.137 & 0.481 \\
\hline
\end{tabular}

genotypic evaluation, 1:1 for the rear crosses and 1:0 for donor parent. These results showed that the observed ratios and the calculated ratios are not significantly different at the 0.05 level of significance; where $p<0.896$ for $\mathrm{F} 2$ and $\mathrm{p}<0.655$ for the $\mathrm{BC} 2 \mathrm{~F} 2$ in phenotypic screening and $\mathrm{p}<0.776$ for $\mathrm{BC} 2 \mathrm{~F} 2$ in molecular marker screening. These ratios and therefore the results are in agreement with the previous work on ALS using Mexico -54 because the donor parent that suggested that the gene for ALS follows the only gene inheritance pattern (Namayanja et al., 2006; Chataika et al., 2010; Sartorato et al., 1999).

The study by Tryphone et al. (2012) performing on ALS using Mexico 54 as resistant parent, confirmed the single gene inheritance. However, other studies showed that the resistance to different $P$. griseola pathotypes could also be controlled by one, two or maybe three dominant or recessive genes (Carvalho et al., 1998). More recently, studies have also demonstrated that the resistance of the cultivars AND 277, Cornell 49242, MAR 1, G 10474 and MAR 2 to some pathotypes were each conditioned by one gene (Nietsche et al., 2000; Ferreira et al., 2000; Mahuku et al., 2002).

Table 2 shows that among 30 samples from individual F1, F2, BC1F1P1, BC1F2P1, BC2F1P1, BC2F2P1 and $\mathrm{BC} 1 \mathrm{~F} 1 \mathrm{P} 2$ plants for phenotypic data, the ratio of $17: 13$, $21: 9,14: 16,17: 13,18: 12,16: 14$ and $27: 3$ for resistant $(R)$ and susceptible (S) and among 20 DNA sample from individual BC2F2 for genotypic data, the ratio of $12: 8$ and
10:10 was observed for g796 and CV542014 markers respectively. The Chi-square value from these findings, $\mathrm{X} 2$ $=0.18$ for $\mathrm{F} 2$ and 0.03 for BC2F2 individuals for phenotypic data, shows that there is no significant difference between the observed and expected ratios at probability of 0.776 or $\mathrm{X} 2 \mathrm{t}=3.841$ (that is, $\mathrm{p}<0.776$ ) as shown in Table 3 . This analysis also revealed a segregation ratio of $1: 1$ for CV541420 as a co-dominant marker associated to Phg-1 gene fit the expected ratios and g796 co-dominant marker associated to gene linked to ALS resistance, was fitted expected ratios at $\mathrm{X} 2 \mathrm{c}=0.05$ and $\mathrm{X} 2 \mathrm{c}=0.45$ at $\mathrm{X} 2 \mathrm{t}=3.841$ CV541420 and g796 markers respectively.

Other previous studies using molecular markers reported similar observations that resistance to specific isolates of $P$. griseola is just inherited (Mahuku et al., 2004; Ferreira et al., 2000; Carvalho et al., 1998). It had been also found in the genotype AND 277 that its resistance to ALS is being conferred by single gene phg-1 (Ragagnin et al., 2005). When the genes are simply inherited then one can easily pyramid genes for resistance to ALS, thus overcoming the difficulty of high degree of pathogenic variability as reported by Sartorato et al. (1999).

\section{Heritability of angular leaf spot}

The estimated narrow sense heritability using the F2 and backcross generations for the cross KT-ABC001 × AND277 
was found to be 0.975 ; this means that nearly 95.7 look after the trait from the parents has been transferred to the offspring and therefore the contribution of genes is above the environmental effects. These results accept as true with what was reported by Amaro et al. (2007) that the resistance to angular leaf spot normally features a relatively high heritability values and plants are often phenotypically selected for recombination in the early generation.

Some other studies revealed that the heritability for reaction to angular leaf spot was varied from 44.44 to $58.86 \%$ and it had been suggested that in the case of low heritability, marker assisted selection is more advantageous (Melo et al., 2002 cited by Teixeira et al., 2005). It has also been reported that there is a complex interaction between genotype and environment which also gives the idea choose on the adoption of indirect selection supported molecular markers (Teixeira et al., 2005).

\section{Correlation between molecular and phenotypic screening to angular leaf spot resistance}

Data from phenotyping was compared with the molecular marker data to assess the reliability of MAS as a tool in breeding for disease resistance. The coefficient of correlation between phenotypic and molecular screening for ALS was found to be -0.658 for CV542014 marker. This high and negative correlation coefficient indicates that one has high chance of success in using molecular markers for screening for disease resistance. The probability occurring by chance is $p<0.001$, which indicates high correlation thus in early generations when number of segregating plants are high; one can believe molecular marker data to equally determine the phenotype.

This correlation is additionally supported by the Chi square test that both phenotypic and genotypic data presented single gene inheritance. This has also been observed in previous studies using marker assisted selection where both ratios from the molecular marker analysis from the field screening were not significantly different from those of Mendelian inheritance (Mukeshimana et al., 2005; Namayanja et al., 2006). It has been reported that the recovery of superior individuals based solely on phenotyping is insufficient because some traits are of low heritability or it is difficult to make favorable conditions for selection as the case for disease resistance. In contrast to the present, the molecular markers are highly heritable and unaffected by the environment. This indicates that there is a requirement to include the molecular marker techniques in selection process in breeding programs so as to hasten the breeding work especially when the trait that is to be selected is of low heritability or its conditions for selection can hardly be set as the case for disease resistance. Aside from all that, there was a requirement to prove that there was high correlation between the molecular marker and the trait to be selected; then, one is often confident and sure of using MAS within the following generations of selection. It has also been cautioned that one should never assume that MAS is necessarily superior to phenotypic selection which for a few traits are often as effective and efficient because the use of molecular markers (Blair et al., 2008). Aside from these correlations being useful in selection, also since there was no one to one correlation, then, the chances that there exists some variability among the isolates used that reacts differently to the genotype regardless of the presence of the genes for resistance to the disease in question.

\section{Phenotypic and molecular marker evaluation of anthracnose resistant gene inheritance}

Disease symptom development started during the fourth day after inoculation. The symptoms were observed to be skewed on different ends among the parents and progenies while in AND277 the score was within the resistant side (1 to 3 ) and in recurrent parent (KT-ABC001) line and Red wolaita (susceptible check) on the susceptible side (7 to 9). In F1 populations, the score was also within the resistant side with few susceptible plants as it was expected and in F2 populations the scores were distributed along the scale but it skewed to the left side showing more of the resistant plants than the susceptible ones. Within the backcrosses, the distribution was almost normal in BC1F1P1 showing equal distribution of plants among the susceptible and resistant ones and in BC1F1P1, the scores concentrated to the resistant sides. The frequency of phenotypic classes within the disease score for resistance and susceptibility reaction to the pathogen in F1, F2 and backcrosses population obtained from the cross between KT-ABC and AND277 and therefore the segregation classes as per molecular marker TGA1.1 gene for ANT resistance was shown in Table 2. Segregation ratios were 3:1 and 1:1 (resistant:susceptible) for the $\mathrm{F} 2, \mathrm{BC} 2 \mathrm{~F} 2$ populations in phenotypic evaluation respectively. In genotypic evaluation, 1:1 ratio was observed for the BC2F2 (resistant to susceptible) respectively, these result shows that the observed ratios and the calculated ratios are not significantly different at the 0.05 level of significance; where $X^{2}=0.71$ for $F 2$ and $\mathrm{X}^{2}=0.03$ for $\mathrm{BC} 2 \mathrm{~F} 2$ in phenotypic screening.

For BC2F2 in molecular marker (TGA1.1) screening, $X^{2}=0.05$, therefore the results are in agreement with the previous work on ANT using AND277 because the donor parent suggested the gene for ANT follows the only gene inheritance pattern (Alzate-Marin et al., 2003). This result is also according to those of Alzate-Marin et al. (2003) and Carvalho et al. (1998) showing that resistance to the ANT and ALS pathogens in AND 277 is monogenic and dominant.

Pyramiding ANT and ALS resistance genes are the most focus of the many bean breeding programs throughout the 
Table 4. Frequencies of phenotypic and genotypic classes for ANT resistance.

\begin{tabular}{|c|c|c|c|c|c|c|}
\hline \multirow{2}{*}{ Parent/Cross/Marker } & \multirow{2}{*}{ Generation } & \multicolumn{2}{|c|}{ Number of plants } & \multirow{2}{*}{ Expected ratio } & \multirow[t]{2}{*}{$\mathrm{X}^{2} \mathrm{c}$} & \multirow{2}{*}{$\mathrm{X}^{2} \mathrm{t}$ at $\mathrm{df}=\mathbf{1}$} \\
\hline & & Resistance & Susceptible & & & \\
\hline KT-ABC & P1 & 0 & 30 & - & - & - \\
\hline AND277 & P2 & 30 & 0 & - & - & - \\
\hline $\mathrm{P} 1 \times \mathrm{P} 2$ & $\mathrm{~F} 1$ & 17 & 13 & $1: 1$ & - & - \\
\hline $\mathrm{F} 1 \mathrm{XF1}$ & F2 & 20 & 10 & $3: 1$ & 0.71 & 3.841 \\
\hline $\mathrm{P} 1 \times \mathrm{F} 1$ & $\mathrm{BC} 1 \mathrm{~F} 1 \mathrm{P} 1$ & 15 & 15 & $1: 1$ & - & \\
\hline P2 XF1 & $\mathrm{BC} 1 \mathrm{~F} 1 \mathrm{P} 2$ & 28 & 2 & $1: 0$ & 1.19 & 3.841 \\
\hline $\mathrm{P} 1 \times \mathrm{BC} 1 \mathrm{~F} 1$ & $\mathrm{BC} 1 \mathrm{~F} 2 \mathrm{P} 1$ & 16 & 14 & $1: 1$ & - & - \\
\hline $\mathrm{P} 1 \times \mathrm{BC} 1 \mathrm{~F} 2$ & $\mathrm{BC} 2 \mathrm{~F} 1 \mathrm{P} 1$ & 17 & 13 & $1: 1$ & - & - \\
\hline $\mathrm{P} 1 \times \mathrm{BC} 2 \mathrm{~F} 1$ & $\mathrm{BC} 2 \mathrm{~F} 2 \mathrm{P} 1$ & 16 & 14 & $1: 1$ & 0.03 & 3.841 \\
\hline TGA1.1(Co-14 $)$ & $\mathrm{BC} 2 \mathrm{~F} 2 \mathrm{P} 1$ & 10 & 10 & $1: 1$ & 0.05 & 3.841 \\
\hline
\end{tabular}

globe (Ragagnin et al., 2005; Miklas and Singh, 2007). Co$1^{4}$ is one among the most genes utilized in ANT resistance breeding programs because of its ample resistance spectrum. Similarly, Phg-1 is employed for resistance to ALS due to their physical linkage and -cis configuration at $5 \mathrm{CM}, \mathrm{Co}-1^{4}$ and Phg-1 tend to be inherited together yet are often indirectly monitored with the CV542014 and TGA1.1 markers. The results were obtained using marker TGA1.1 for the gene for $\mathrm{Co}_{-1} 1^{4}$ ANT resistance.

Table 4 shows that among 30 samples from individual $\mathrm{F} 2, \mathrm{BC} 2 \mathrm{~F} 2 \mathrm{P} 1$ and BC1F1P2 plants for phenotypic data, the ratio of $20: 10,16: 14$ and $28: 2$ was observed for resistant $(R)$ and susceptible $(S)$ respectively. And among 20 DNA sample from individual BC2F2P1 for genotypic data (Figure 1), the ratio of 10:10 was observed. The Chi square value from these findings, $\mathrm{X} 2 \mathrm{c}=0.71$ for $\mathrm{F} 2$ and 0.03 for BC2F2 individuals shows that there is no significant difference between the observed and expected ratios at $X^{2}=0.05$ where $X^{2} t$ at $d f=1$ is 3.841 as shown in Table 4. This analysis also revealed a segregation ratio of 1:1 for TGA1.1 as a co-dominant marker associated to Co$1^{4}$ gene fit the expected ratios linked to ANT resistance, at $\mathrm{X} 2 \mathrm{c}=0.05$.

It was also found in the genotype AND 277 that its resistance to ANT is being conferred by single dominant gene Co- $1^{4}$ (Ragagnin et al., 2005).

\section{Heritability of anthracnose}

The estimated narrow sense heritability using the F2 and backcross generations for the cross KT-ABC 001x AND277 was found to be 0.95 , this means that nearly $95 \%$ of the trait from the parents has been transferred to the offspring and therefore the contribution of genes is higher than the environmental effects. This result is in agreement with the findings of Ragagnin et al. (2005). The resistance to anthracnose disease normally features a relatively high heritability values and plants are often phenotypically selected for recombination in the F2 generation.
Various studies revealed the heritability for reaction to anthracnose was varied from 55.8 to $84.5 \%$ and it had been suggested that in the case of low heritability, marker assisted selection is more advantageous (Alzate-Marin et al., 1997). It has also been reported that there is a complex interaction between genotype and environment which also gives the idea in deciding on the adoption of indirect selection based on molecular markers (Teixeira et al., 2005).

\section{Correlation between molecular and phenotypic screening to anthracnose}

The result from phenotypic screening was compared with the result from the molecular marker screening to assess the reliability of MAS as a tool in breeding for disease resistance. The coefficient of correlation between phenotypic and molecular screening for ANT was found to be, -0.739 (Table 3). This high and negative correlation coefficient indicates that one has high chance of success in using molecular markers for screening for disease resistance. The probability of this occurring accidentally is $p<0.001$ which indicates when number of segregating plants is high; one can believe molecular marker data to equally determine the phenotype. This correlation is additionally supported by the chi square test that both phenotypic and genotypic data presented single gene inheritance. This has also been observed in previous studies using marker assisted selection where both ratios from the molecular marker analysis from the field screening were not significantly different from those of Mendelian inheritance (Mukeshimana et al., 2005; Namayanja et al., 2006). It has been reported that the recovery of superior individuals based solely on phenotyping is insufficient because some traits are of low heritability. In contrast to the present, the molecular markers are highly heritable and unaffected by the environment.

This implies that there was a requirement to include the 


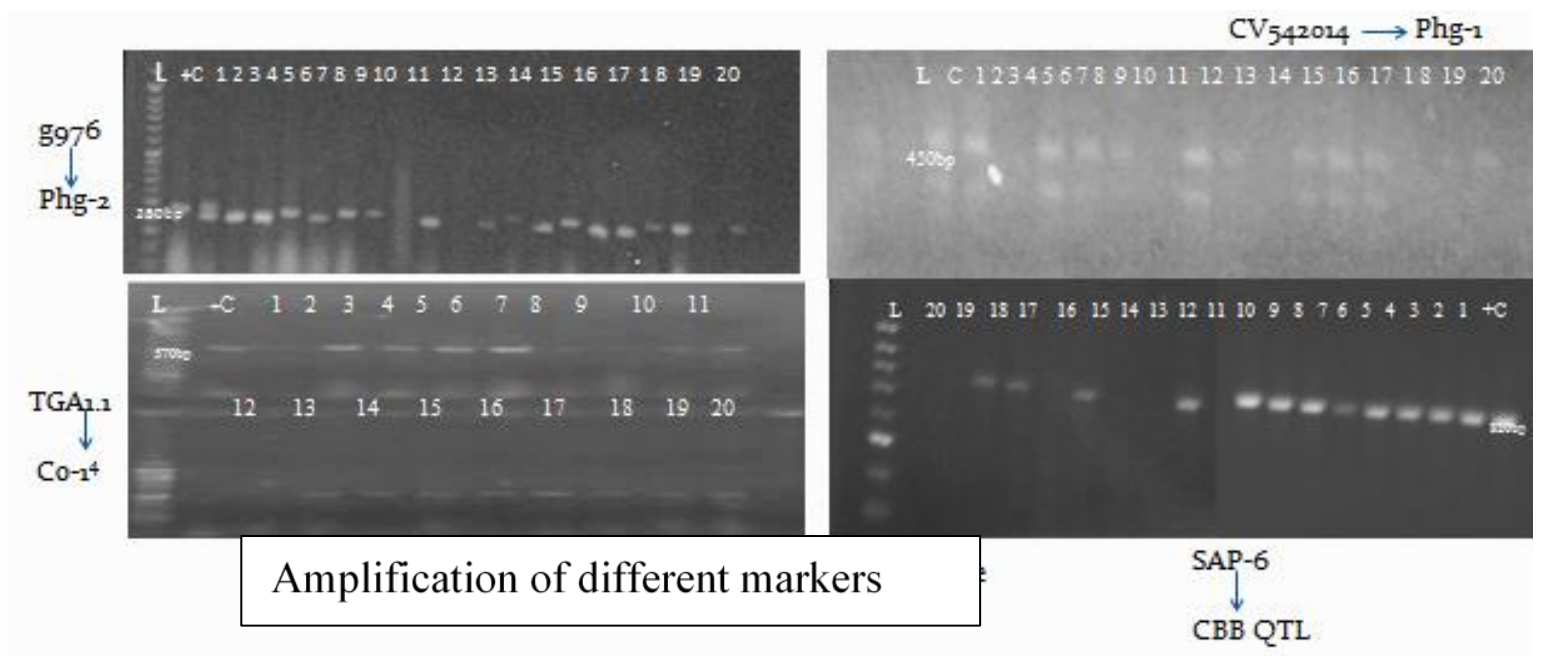

Figure 1. Sample gel for multiple gene selection ALS (Phg-2 \& Phg-1 gene), ANT (Co-1 ${ }^{4}$ gene) and CBB QTL of parents and BC2F2 generation.

molecular marker techniques within the selection process of breeding programs. Molecular markers can hasten the breeding work especially when the trait to be selected is of low heritability or its conditions for selection can hardly be set as the case for disease resistance. The presence of high correlation between the molecular marker and therefore the trait to be selected indicates assurance of using MAS in selection process of the subsequent generations. It has also been cautioned that one should never assume that MAS is necessarily superior to phenotypic selection which for a few traits are often as effective and efficient as the use of molecular markers (Blair et al., 2008). Aside from these correlations being useful in selection, also since there was no one to one correlation, then, the chances that there exists some variability among the isolates used that reacts differently to the genotype regardless of the presence of the genes for resistance to the disease in question.

This necessitates the study of the pathogen variability so as to come up with an integrated management which will consider pathogen variability as a part of the breeding strategy for disease resistance.

\section{Selection of plants with combined resistance to ALS, ANTH and CBB}

The aim of evaluation was to seek out plants with combined markers or multiple genes for resistance of three diseases, ALS, ANT and CBB. Selection was done among the segregating BC2F2 population by using phenotypic data and molecular markers. Having found that the genes for ALS, ANT and CBB are dominant and have simple inheritance pattern. This is often an indication that there is a high probability of choosing plants with; all the four desirable genes, three of the genes, two of genes and single gene for each disease, and none of the genes (Table 5). During selection process, the g796 and CV542014 marker were used to screen for Phg-2 and Phg1 genes respectively that confers resistance to ALS. TGA1.1 marker was wont to screen co-14 gene, that confer resistance ANT and SAP-6 marker was wont to screen CBB QTL that confer resistance to CBB.

There were five gene pyramid groups with two to four pyramided resistance genes namely, Phg-1+phg-2+co$1^{4}+\mathrm{cbb}$ qtl, Phg-1+phg-2+co-14, Phg-1+ co-14 + cbb qtl, Phg- $1+$ co-14 and phg-2 +cbb qtl (Table 5). The Phg$1+$ phg-2+co- $1^{4}+\mathrm{cbb}$ qtl and the Phg-1+co-14 + cbb qtl groups conferred resistance to all or any of the four isolates (ALS, ANT and CBB). The Phg-1+phg-2+co-14 and Phg-1+ co- $1^{4}$ pyramid groups conferred resistance to ALS and ANT but were overcome by CBB while the phg-2 +cbb qtl pyramid group was overcome by ALS and ANT but conferred resistance to only CBB.

The pyramid group "Phg1+phg2+co- $1^{4}+\mathrm{cbb}$ qtl" had the smallest amount mean severity $1 \pm 0.00$ followed by group "Phg- $1+\mathrm{co}-1^{4}+\mathrm{cbb}$ qtl" with a score of $1.11 \pm 0.0$ while group "No-gene" had the highest mean severity of $8 \pm 0.00$. In general, gene pyramid "Phg1+phg2+co-14+cbb qtl" recorded low mean disease severity compared to the triple, double and single gene combinations implying that pyramiding was a beneficial strategy in reducing leaf severity across the three pathogens. This is often evident within the amount of leaf symptoms expressed on leaves from plants with "Phg- $1+\mathrm{co}-1^{4}+\mathrm{cbb}$ qtl" combination compared with those expressed on leaves with "Phg1+phg2+co14+cbb qtl" combination. Symptoms of ALS, ANT and CBB were not significantly different within the former than within the later, though both were deemed highly resistant reactions. Among the 2 gene pyramids Phg1+phg2+co-14+cbb qtl and Phg-1+co-14+cbb qtl, had similar mean effect although phg-2+ cbb qtl was overcome 
Table 5. Gene pyramid groups and their severity mean with three pathogens.

\begin{tabular}{lcccc}
\hline \multirow{2}{*}{ Pyramid groups } & \multicolumn{4}{c}{ Mean severity of isolates } \\
\cline { 2 - 5 } & ALS & ANT & CBB & Grand mean \\
\hline Phg- $1+$ phg-2+co-14+cbb qtl & $1.00 \pm 0.00$ & $1.00 \pm 0.00$ & $1 \pm 0.00$ & $1.00 \pm 0.00$ \\
Phg-1+phg-2+co-1 & $1.66 \pm 0.57$ & $1.66 \pm 0.57$ & $7.33 \pm 0.57$ & $3.55 \pm 0.57$ \\
Phg-1+ co-14+ cbb qtl & $1.00 \pm 0.000$ & $1.33 \pm 0.57$ & $1.00 \pm 0.00$ & $1.11 \pm 0.19$ \\
Phg-1+ co-14 & $1.33 \pm 0.57$ & $2.33 \pm 0.57$ & $7.33 \pm 0.57$ & $3.66 \pm 0.57$ \\
phg-2+ cbb qtl & $4.33 \pm 0.57$ & $6.00 \pm 0.00$ & $2 \pm 0.00$ & $4.11 \pm 0.19$ \\
phg-2 & $8.33 \pm 0.57$ & $7.66 \pm 0.57$ & $7.66 \pm 0.57$ & $7.89 \pm 0.57$ \\
cbb qtl & $6.33 \pm 0.57$ & $7.00 \pm 0.00$ & $1.33 \pm 0.57$ & $4.89 \pm 0.38$ \\
No-gene & $8.00 \pm 0.00$ & $8.00 \pm 0.00$ & $8 \pm 0.00$ & $8.00 \pm 0.00$ \\
HSD (0.05) & 0.52 & 0.68 & 0.78 & 0.66 \\
S.E.D & 0.33 & 0.31 & 0.34 & - \\
CV & 11.94 & 17.21 & 17.76 & - \\
\hline
\end{tabular}

by the ALS. The "phg-2+ cbb qtl" combination was not effective for ALS and ANT case since it only afforded resistance to the $\mathrm{CBB}$, rather it is the foremost effective to combine phy- 1 with others because it is linked with Co- $1^{4}$ and is broad resistant for many of African races. Kelly and Vallejo (2004) reported that the Co- $1^{4}$ gene possesses a high breeding value against Andean races of $C$. lindemuthianum, but is vulnerable to weaker Mesoamerican races and therefore the linked phg-1 possess resistance to most of Andean $P$. greaseola. This might explain the great resistance related to those genes both singly and together with other genes.

Disease severity means across the four isolates were significantly different from one another (HSD0.05 $=0.52$, 0.68 and 0.78 ) for ALS, ANT and CBB respectively for all the pyramid groups (Table 5), with the exception of groups Phg1+phg2+co- $1^{4}+\mathrm{cbb}$ qtl $(1 \pm 0.00)$ and Phg- $1+\mathrm{co}-1^{4}+\mathrm{cbb}$ qtl (1.1 \pm 0.19$)$, Phg-1+ co-1 $^{4} \quad(3.66 \pm 0.57)$ and Phg1+ph2+co-14 (3.55 $\pm 0.570 .00)$.

\section{Conclusions and recommendations}

This study clearly demonstrated that, gene pyramids increase degree and spectrum of resistance against the three diverse pathogen; however, not all pyramids were effective against the pathogens. Some double genes also demonstrated a broad spectrum nature of resistance against three pathogens and in some cases conferred a more effective resistance than some four or three gene pyramids. Therefore, before embarking on an extended and expensive gene pyramiding program caution should be taken in choosing genes which will end in effective gene pyramids offering increased level and spectrum of resistance against different pathogen in a given target location. In some cases, the mere deployment of a single broad-spectrum gene like Co- $1^{4}$ and Phg-1 may suffice, but added benefits could also be realized when it is together with other complementary genes whose modes of single and combined action are well understood.
This work has also substantiated the utilization of MAS in crop improvement in Ethiopia so as to extend the pace of breeding. From the studies, it had been found that, inheritance for pathogens is simple and stable utilizing single dominant gene for ALS and ANT. These results provide strong basis for its use in improvement of common bean in Ethiopia. The correlation between the phenotypic and genotypic data showed strong correlation which makes the utilization of molecular marker more valid. Aside from that, it had been found that there was no one to one relationship (that is, $r<1$ ) suggesting that MAS should not be used alone rather being integrated with phenotypic screening within the field/strong classical breeding at some points to validate the continuing molecular marker use, this may aim at breeding for more adapted common bean lines.

Generally from 20 isolines evaluated with the combination of phenotypic and genotypic techniques, three plants were found with four desired genes and those plants shall be advanced and incorporated to breeding program so as to release variety with immune to ALS, ANT and CBB pathogens. It is therefore suggested that:

1. More studies should be done to see with the pathogen variability and validate the stability of those markers with time because the pathogen as well as the genotypes changes; this may promote improvement of the prevailing tools to suit the growing conditions, present genotypes and possibly new pathogen races.

2. Pathogen characterization variability should be conducted for common bean anthracnose in Ethiopian case.

3. Donor parent (AND277) should be maintained to use in common bean improvement program as source of resistance genes for angular leaf spot and anthracnose diseases.

\section{CONFLICT OF INTEREST}

The authors declare that they have no conflict of interest. 


\section{ACKNOWLEDGEMENT}

Much appreciation goes to the Hawasa University hosting the study and the funding from Kirkhouse Trust to pursue this research work.

\section{REFERENCES}

Abawi, G. S. (1989). Root rots. In: Shwartz H. F., \& PastorCorrales, M. A. Bean production problems in the tropics (pp. 105-158). CIAT, Cali, Colombia.

Allen, D. J., \& Lenne J. M. (1998). Diseases as constraints to production of legumes in agriculture. In: Allen, D. J., \& Lenne, J. M. (eds.). Pathology of food and pasture legumes. CAB International, Wallingford, UK. Pp. 1-61.

Alzate-Marin, A.L. and Sartorato, A. (2004). Analysis of the pathogenic variability of Colletotrichum lindemuthianum in Brazil. Annual Report Bean Improvement Crop, 47, 241-242.

Alzate-Marin, A. L., Bafa, G. S, de Paula Junior, T. J., Carvalho, G. A., Baros, E. G., \& Moreira, M. A. (1997). Inheritance of anthracnose resistance in common bean differential cultivar AB 136. Plant Diseases, 81, 996-998.

Amaro, G. B., Abreu, Â. D. F. B., Ramalho, M. A. P., \& Silva, F. B. (2007). Phenotypic recurrent selection in the common bean (Phaseolus vulgaris $\mathrm{L}$ ) with carioca-type grains for resistance to the fungi Phaeoisariopsis griseola. Genetics and Molecular Biology, 30(3), 584-588.

Aparício, B. H. E. (1998). Caracterizacion de la diversidad molecular y la virulencia de aislamientos del hongo. Phaeoisariopsis griseola.

Beebe, S., Ramirez, J., Jarvis, A., Rao, I. M., Mosquera, G., Bueno, J. M., \& Blair, M. W. (2011). Genetic improvement of common beans and the challenges of climate change. In: Crop adaptation to climate change, Pp. 356-369.

Blair, M. W., Buendía, H. F., Giraldo, M. C., Métais, I., Peltier, D. (2008). Characterization of AT-rich microsatellite markers for common bean (Phaseolus vulgaris $\mathrm{L}$.) based on screening of non-enriched small insert genomic libraries. Theoretical and Applied Genetics, 118(1), 91-103.

Bliss, F.A. (1980). Common bean. In: Fehr, W. R, \& Hadley, H. H. (eds.). Hybridization of crop plants. Crop Science Society of America, Madison, WI. Pp. 273-284.

Buishand, T. J. (1956). The crossing of beans (Phaseolus spp.). Euphytica, 5(1), 41-50.

Broughton, W. J., Hernandez, G., Blair, M., Beebe, S., Gepts, P., \& Vanderleyden, J. (2003). Beans (Phaseolus spp.)-model food legumes. Plant and Soil, 252(1), 55-128.

Burkett-Cadena, M., Kokalis-Burelle, N., Lawrence, K. S., Van Santen, E., \& Kloepper, J. W. (2008). Suppressiveness of rootknot nematodes mediated by rhizobacteria. Biological Control, 47(1), 55-59.

Caixeta, E. T., Borém, A., \& Kelly, J. D. (2005). Development of microsatellite markers based on BAC common bean clones. Crop Breeding and Applied Biotechnology, 5(2), 125133.

Carvalho, G. A., Paula, T. J., Alzate-Marin, A. L., Nietsche, S., de Barros, E. G., \& Moreira, M. A. (1998). Inheritance of resistance to angular leaf spot of common bean in AND 277 to race 63-23 of Phaeoisariopsis griseola and identification of a RAPD marker linked to the resistance gene. Fitopatol Bras, 23, $482-485$

Castro, A. J., Chen, X., Hayes, P. M., \& Johnston, M. (2003).
Pyramiding quantitative trait locus (QTL) alleles determining resistance to barley stripe rust: effects on resistance at the seedling stage. Crop Science, 43(2), 651-659.

Central Statistical Authority (CSA) (2010). Area under production of major crops. Statistical Bulletin. 245, Addis Ababa, Ethiopia.

Chataika, B. Y., Bokosi, J. M., Kwapata, M. B., Chirwa, R. M., Mwale, V. M., Mnyenyembe, P., \& Myers, J. R. (2010). Performance of parental genotypes and inheritance of Angular Leaf Spot (Phaeosariopsis griseola) resistance in the common bean (Phaseolus vulgaris). African Journal of Biotechnology, 9(28), 4398-4406.

Chen, X. M., Line, R. F., \& Leung, H. (1993). Relationship between virulence variation and DNA polymorphism in Puccinia striiformis. Phytopathology, 83(12), 1489-1497.

CIAT (1997). Bean Programme Annual Report (1995). Working document, No 163.

Clare, M. M., Melis, R., Dereta, J., Laing, M., \& Buruchara, R. A. (2010). Identification of sources of resistance to Fusarium root rot among selected common bean lines in Uganda. Journal of Animal \& Plant Sciences, 7(3), 876-891.

De Jesus, W. C., Do Vale, F. X. R., Coelho, R. R., Hau, B., Zambolim, L., Costa, L. C., \& Filho, A. B. (2001). Effects of angular leaf spot and rust on yield loss of Phaseolus vulgaris. Phytopathology, 91(11), 1045-1053.

Deeksha, J., Hooda, K. S., Bhatt, J. C., Mina, B. L., \& Gupta, H. S. (2009). Suppressive effects of composts on soil-borne and foliar diseases of French beans in the field in the western Indian Himalayas. Crop Protection, 28(7), 608-615.

Fernández, M. T., Fernandez, M., Casares, A., Rodriguez, R., \& Fueyo, M. (2000). Bean germplasm evaluation for anthracnose resistance and characterization of agronomic traits: A new physiological strain of Colletotrichum lindemuthianum infecting Phaseolus vulgaris L. in Spain. Euphytica, 114(2), 143-149.

Ferreira, C. F., Borém, A., Carvalho, G. A., Nietsche, S., Paula, T. J., Barros, E. G., \& Moreira, M. A. (2000). Inheritance of angular leaf spot resistance in common bean and identification of a RAPD marker linked to a resistance gene. Crop Science, 40(4), 1130-1133.

Habtu, A., Sache, I., \& Zadoks, J. C. (1996). A survey of cropping practices and foliar diseases of common beans in Ethiopia. Crop Protection, 15(2), 179-186.

Improving common bean productivity: An analysis of socioeconomic factors in Ethiopia and Eastern Kenya. Baseline Report Tropical legumes II. Centro Internacional de Agricultura Tropical-CIAT. Cali, Colombia, 126.

Mahuku, G. S., Jara, C., Cajiao, C., \& Beebe, S. (2003). Sources of resistance to angular leaf spot (Phaeoisariopsis griseola) in common bean core collection, wild Phaseolus vulgaris and secondary gene pool. Euphytica, 130(3), 303-313.

Miklas, P. N., Fourie, D., Wagner, J., Larsen, R. C., \& Mienie, C. M. (2009). Tagging and Mapping Pse-1 Gene for Resistance to Halo Blight in Common Bean Differential Cultivar UI-3. Crop Science, 49(1), 41-48.

Miklas, P. N., Coyne, D. P., Grafton, K. F., Mutlu, N., Reiser, J., Lindgren, D. T., \& Singh, S. P. (2003). A major QTL for common bacterial blight resistance derives from the common bean great northern landrace cultivar Montana No. 5. Euphytica, 131(1), 137-146.

Miller, T., Gepts, P., Kimmo, S., Arunga, E., Chilagane, L. A., Nchimbi-Msolla, S., \& Tedla, Y. R. (2018). Alternative markers linked to the Phg-2 angular leaf spot resistance locus in common bean using the Phaseolus genes marker database. African Journal of Biotechnology, 17(26), 818-828.

Mortensen, C. N. (2005). Detection of Xanthomonas oryzae pv. 
oryzae from rice seeds by liquid assay. In: Seed Health Testing for Bacterial Pathogens. Danish Seed Health Centre for developing countries, Thorvaldsensvej 40, DK-1871, Frederiksberg C, Copenhagen, Denmark. Pp. 65-68.

Mukeshimana, G., Pa neda, A., Rodriguez, C., Ferreira, J. J., Giraldez, R., \& Kelly, J. D. (2005). Markers linked to the bc-3 gene conditioning resistance to bean common mosaic potyviruses in common bean. Euphytica 144:291-299

Mutlu, N., Miklas, P., Reiser, J., \& Coyne, D. (2005). Backcross breeding for improved resistance to common bacterial blight in pinto bean (Phaseolus vulgaris L.). Plant Breeding, 124(3), 282-287.

Namayanja, A., Buruchara, R., Mahuku, G., Rubaihayo, P., Kimani, P., Mayanja, S., \& Eyedu, H. (2006). Inheritance of resistance to angular leaf spot in common bean and validation of the utility of resistance linked markers for marker assisted selection out side the mapping population. Euphytica, 151(3), 361-369.

Nietsche, S., Borém, A., Carvalho, G. A., Rocha, R. C., Paula Jr, T. J., De Barros, E. G., \& Moreira, M. A. (2000). RAPD and SCAR markers linked to a gene conferring resistance to angular leaf spot in common bean. Journal of Phytopathology, 148(2), 117-121.

Pastor-Corrales, M. A., \& Tu, J. C. (1989). Anthracnose (pp. $77-$ 104). In: Schwartz H. F., \& Pastor-Corrales, M. A. (eds.). 2nd ed. Bean production problems in the tropics. CIAT, Cali, Colombia. 560pp

Ragagnin, V., Sanglard, D., de Souza, T. L., Costa, M., Moreira, M., \& Barros, E. (2005). A new inoculation procedure to evaluate angular leaf spot disease in bean plants (Phaseolus vulgaris L.) for breeding purposes. Bean Improvement Cooperative, 48, 90-91.

Rezene, Y., Tesfaye, K., Mukankusi, C., Arunga, E., \& Gepts, P. (2018). Simple and rapid detached leaf technique for screening common beans (Phaseolus vulgarise L.) in vitro against angular leaf spot (Pseudocercospora griseola) disease. African Journal of Biotechnology, 17(35), 1076-1081.

Sartorato, A., Nietsche, S., Barros, E. G., \& Moreira, M. A. (1999). Scar marker linked to angular leaf spot resistance gene in common bean. Annual report of the bean improvement cooperative. 42, 23-24.
Singh, S. P., Gepts, P., \& Debouck, D. G. (1991). Races of common bean (Phaseolus vulgaris, Fabaceae). Economic Botany, 45(3), 379-396.

Teixeira, F. F., dos Santos, J. B., Ramalho, M. A. P., Abreu, Â., Guimarães, C. T., \& de Oliveira, A. C. (2005). QTL mapping for angular leaf spot in common bean using microssatellite markers. Embrapa Milho e Sorgo-Artigo em periódico indexado (ALICE). Crop Breeding and Applied Biotechnology, $5(3), 272-278$

Tesfaye, B. (1997). Loss assessment study on haricot bean due to Anthracnose. Pest Management Journal of Ethiopia, 1(1\&2), 69-72.

Wortmann, C. S., Brink, M., \& Belay, G. (2006). Phaseolus vulgaris $\mathrm{L}$. (common bean). Record from PROTA4U. Brink, $M$. \& Belay, G. (Editors). PROTA (Plant Resources of Tropical Africa/Ressources végétales de l'Afrique tropicale), Wageningen, Netherlands.

Xu, Y., \& Crouch, J. H. (2008). Marker-assisted selection in plant breeding: From publications to practice. Crop Science, 48(2), 391-407.

Ye, G., \& Smith, F.K. (2008). Marker-assisted gene pyramiding for inbred line development: basic principles and practical guidelines. International Journal of Plant Breeding, 2(1),1-10.

Yesuf, M. (2005). Seed borne nature of Colletotrichum lindemuthianum and its epidemic on common beans in the major bean growing areas of Ethiopia. A PhD Thesis in Tropical Agriculture. Graduate School, Kasetsart University.

e Silva, L. O., Singh, S. P., \& Pastor-Corrales, M. A. (1989). Inheritance of resistance to bacterial blight in common bean. Theoretical and applied genetics, 78, 619-624. 